\title{
Relevance of Resin for Photoelasticity
}

\author{
Adriana Vieira. Martins*a ${ }^{\circledR}$, Wellington Márcio dos Santos Rocha ${ }^{a}$, Nelson Renato França Alves \\ Silva ${ }^{a}$, Rodrigo de Castro Albuquerque ${ }^{a}$, Allyson Nogueira Moreira ${ }^{a}$, Rodrigo Richard da Silveira ${ }^{a}$, \\ Cláudia Silami Magalhães ${ }^{a}$, Wellington Antonio Soares ${ }^{b}$. \\ ${ }^{a}$ Departmento de Odontologia Restauradora, Universidade Federal de Minas Gerais, Belo Horizonte, \\ Brasil. \\ ${ }^{b}$ Divisão de Tecnologia de Reator, Centro de Desenvolvimento de Tecnologia Nuclear (CDTN/CNEN), \\ Belo Horizonte, Brasil.
}

Received: December 27, 2018; Revised: November 13, 2019; Accepted: November 14, 2019

\begin{abstract}
The goal of this study is to test photoelastic resins for manufacturing models with teeth and/or implants under chewing load. Four commercial brands have been chosen: Araldite (Ciba Chemicals), Flexible GIV-Rigid GIV (Polipox) and PL2 (Measurements Group). Nine discs were manufactured, four of them from each of the photoelastic resin brands and five from different proportions of mixture between Flexible GIV and Rigid GIV. All the models were subjected to the diametral compression test, and observed in a circular polariscope. The first order fringe has always been adopted as a benchmark to calculate the photoelastic constant. To the load of interest (150 Newtons), Flexible GIV resin showed areas that followed the elastic regime. Residual stresses for the resin PL2 and persistence of bubbles within the model were observed. Rigid GIV Resin generated the first fringe order only at 280 Newtons load. Araldite resin behaved within the elastic regime and there were no areas with excessive concentration of fringes. The models generated from the manual mixing generated non-homogeneous photoelastic images. The Araldite resin showed to be the most suitable material for manufacturing birefringent models with teeth and/or implants under chewing load.
\end{abstract}

Keywords: photoelastic resins, two-dimensional photoelasticity, dental models.

\section{Introduction}

Photoelasticity is a stress analysis technique, based on the mechanical birefringence property, inherent to some transparent polymers. It also uses the properties of polarized light and mechanical loads on bodies of interest ${ }^{1-6}$.

A fundamental point in the photoelastic analysis is the choice of the proper resin which must present specific properties such as transparency to light, workability, absence of residual stresses and, yet, being a birefringent material ${ }^{6,7}$. Besides that, researches in the dental field who make use of this experimental method for stress analysis, especially where masticatory loads have to be reproduced, should consider, together with other aspects, the sensitivity of those materials to the load itself. In this way, a photoelastic material would be properly indicated for the procedure, taking into account its behavior in forming sharp fringes within its elastic regimen, when loaded according to the real clinical situation ${ }^{3}$. The photoelastic technique is the easiest one for conditions which better reproduce the actual loads ${ }^{8-13}$.

The aim of this work is to study some photoelastic resins for the construction of transparent models that be closest as possible to a clinical tooth and/or implant condition under masticatory load. Additionally, it is meant to produce meaningful knowledge for the choice of the most adequate photoelastic resin among four commercial brands most used in laboratory studies.

*e-mail: adriana@adrianavieiramartins.com.br

\section{Literature Review}

The photoelasticity theory was first drawn by Sir David Brewster in 1816, when he discovered that transparent materials having an isotropic character could become anisotropic when submitted to mechanical loads ${ }^{5}$. The dentistry study that first made use of this method dates from 1935. Since then, it became extensively used in several dental areas. Furthermore, it is still very employed as a quality control tool.

The main advantage of this technique lies on the simultaneous visualization of the stresses generated in the loaded models, when those stresses can be calculated and photographed. On the other hand, the need for using models closest as possible to reality is a limitation of the method, since those models are built from materials which are different from those you are supposed to emulate ${ }^{1 .}$ An adequate choice of the resin, considering the necessary characteristics of a material being classified as photoelastic, is then the main fact that attests the method is reliable $e^{1,6-17}$.

For a photoelastic trial, it is necessary to use, for constructing the models, birefringent materials able to fulfill some minimal requirements. Transparency to the light used in the polariscope is fundamental ${ }^{17}$, while the lost of transparency can occur due to two reasons: (1) decrease in indexes of refraction of the constituent materials and (2) trapped air. In both cases, there is an alteration in the photoelastic medium properties leading to light dispersion, therefore reducing the material transparency ${ }^{18-20}$. 
Another point considered is the possibility of the material to suffer the "the border effect", a phenomenon related to the water absorption and evaporation by the plastic materials, resulting in changes in the model dimensions and consequently in the internal stresses ${ }^{17}$.

The photoelastic sensitivity to induced stresses on the model is a very relevant characteristic and it is represented by a photoelastic constant ${ }^{6}$. A highly elastic module will guarantee that the material, when loaded, will not have its shape altered ${ }^{16}$. From the association of those two properties, the photoelastic constant and the elasticity module, a third property to be considered, known as figure of merit measures how sensitive are those resins. Ideally, the value of the figure of merit should also be the highest as possible and keep constant during the test. It is common, within the photoelastic resins, the presence of intrinsic stresses known as residual stress. Having the photoelastic materials in mind, those stresses will interfere upon the results, which makes their extrapolation invalid ${ }^{1,21}$.

Ideally, the model materials should emulate the behavior, in clinical situations, of what one intends to reproduce 1. In the case of models that simulate dental tissues, their properties should be close to those related to enamel and dentin. Such structures are responsible for receiving the chewing efforts, and the stresses generated are transmitted to the dental support tissues. For supporting tissues, in this case, the alveolar bone, the photoelastic material for its simulation should, at a minimum, be able to work within its elastic limit. Moreover, it best provides a photoelastic response compatible with the load intensity imposed on photoelastic models, and preferably from "loads that best emulate a real condition" 13 . And since all the factors that act in the oral medium cannot be faithfully reproduced, at least a material should be used which best furnishes a photoelastic answer compatible to the load intensity being imposed on the photoelastic models when submitted to the stresses. So that the fringes seen on the polariscope are clear and well delimited, allowing extrapolating the results to the clinical condition.

Thus, the goal of this study was to test some properties of four photoelastic materials for constructing transparent models that be closest as possible to a clinical tooth and/ or implant condition under masticatory load. Producing meaningful knowledge for selecting the most adequate photoelastic resin among four commercial brands most used in laboratory studies is also pursued.

\section{Methods}

\subsection{Photoelastic Resins in Odontology}

Four very required commercial brands in two-dimensional test of resins were chosen, for constructing models to submit to a condition that simulates the occlusal loads. The option for the mentioned brands (Chart 1) was based on an extensive recommendation in the pertinent literature $8,2,3,14,22,23$.

Chart 1 shows resins based on epoxy and polycarbonate and their presentation is in the liquid form (pre-polymer), plus a curing agent, both of which have to be mixed and carefully manipulated at the moment of the photoelastic model construction. They are indicated for work at room temperature. All the materials generate translucent and colorless mixtures, except the PL2 resin, which produced a yellowish liquid. The amount of material used must be previously calculated and the ratio of the two components must follow the manufacturer's instructions. For the handling of the materials cited in Chart 1 , some precautions were taken, since they can cause allergic reactions. Therefore, handling of those resins was performed in an airy place, using rubber gloves, protection goggles and masks, according to some manufacturers' orientations.

\subsection{Preparation of specimens - scaling and modeling of discs}

The resins sensitivity was determined by using a transparent disc, under diametral compression load; and, during the photoelastic test, by forcing a determined fringe to pass through the center of the disc, while generated images were recorded. This is one of the standard procedures for determining the photoelastic resin sensitivity.

Initially a metallic disc, having smooth surfaces and measuring $50 \mathrm{~mm}$ in diameter and $5 \mathrm{~mm}$ thick, was glued to the bottom and at the center of an acrylic box, fully collapsible [12]. Industrial molding silicone (SILICONE 8001 - Casa da Resina e do Silicone) manipulated in the ratio of $100 \mathrm{~g}$ base pasta to $3 \mathrm{~g}$ catalyst, was slowly poured into the box, to cover all the disc, in the meantime creating a cover thick enough for recovering its shape after handling.

Nine molds were made, one for each photoelastic resin brand, plus other five for housing the different ratios of mixing between the resins Flexible GIV (Polipox) and Rigid GIV (Polipox), according to Chart 2. Each resin was carefully poured into the moldings, to minimize the formation of bubbles. After the polymerization time for each material, the nine discs were removed from the molding (Figure 1).

Chart 1. Commercial brands, proportion of mixture and visual characteristics of the four resins used in this study.

\begin{tabular}{|c|c|c|}
\hline Names/Commercial brands & Mixture's proportions & Visual characteristics \\
\hline $\begin{array}{l}\text { Araldite GY 279-BR and hardner Aradur HY2963-C (Produtos } \\
\text { Químicos Ciba S/A do Brasil). }\end{array}$ & 100pp resin / 42pp hardner & Translucent and shiny aspect \\
\hline Flexível GIV and hardner GIV (Polipox) & $100 \mathrm{pp}$ resin / $50 \mathrm{pp}$ hardner & Translucent and shiny aspect \\
\hline Rígida GIV and hardner GIV (Polipox) & $100 \mathrm{pp}$ resin / $50 \mathrm{pp}$ hardner & Translucent and shiny aspect \\
\hline PL2 (Measurements Group, Raleigh, NC, USA) & $100 \mathrm{pp}$ resin $/ 100 \mathrm{pp}$ hardner & Yellowish appearance \\
\hline
\end{tabular}


Chart 2. Number of each model, brands and mixture ratio, disc dimensions, experimentally calculated photoelastic constant, and necessary load magnitude for forming the first order fringe.

\begin{tabular}{|c|c|c|c|c|c|}
\hline $\begin{array}{l}\text { Models Model } \\
\text { number }\end{array}$ & $\begin{array}{c}\text { Brands and mixture } \\
\text { ratio }\end{array}$ & $\begin{array}{l}\text { Diameter } \\
(\mathbf{m m})\end{array}$ & $\begin{array}{l}\text { Thickness } \\
\text { (mm) }\end{array}$ & $\begin{array}{c}\mathbf{f} \boldsymbol{\sigma} \\
(\mathbf{N} / \mathbf{m})\end{array}$ & $\begin{array}{l}\text { Load magnitude intensity } \\
\text { (Newtons) First order } \\
\text { fringe }\end{array}$ \\
\hline Model 1 & Rigid GIV (100\%) & 50.4 & 5 & 14171.1 & 280.3 \\
\hline \multirow{2}{*}{ Model 2} & Rigid GIV (75\%) & 50.4 & 5 & 1097.1 & 21.7 \\
\hline & Flexible GIV (25\%) & & & & \\
\hline \multirow{2}{*}{ Model 3} & Rigid GIV (50\%) & 50.4 & 5 & 638.5 & 12.6 \\
\hline & Flexible GIV (50\%) & & & & \\
\hline \multirow{2}{*}{ Model 4} & Rigid GIV (25\%) & 50.4 & 5 & 585.2 & 11.6 \\
\hline & Flexible GIV (75\%) & & & & \\
\hline Model 5 & PL2 (100\%) & 50.4 & 5 & 4714.3 & 93.3 \\
\hline \multirow{2}{*}{ Model 6} & Rigid GIV (90\%) & 50.4 & 5 & 195.9 & 3.9 \\
\hline & Flexible GIV (10\%) & & & & \\
\hline \multirow{2}{*}{ Model 7} & Rigid GIV (95\%) & 50.4 & 5 & 152.0 & 3.0 \\
\hline & Flexible GIV (5\%) & & & & \\
\hline Model 8 & Araldite $(100 \%)$ & 50.4 & 5 & 8518.0 & 168.5 \\
\hline Model 9 & Flexible GIV $(100 \%)$ & 50.4 & 5 & 366.5 & 8.3 \\
\hline
\end{tabular}

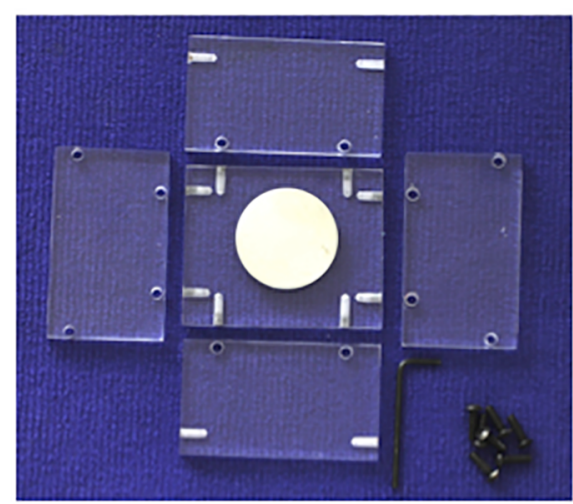

(a)

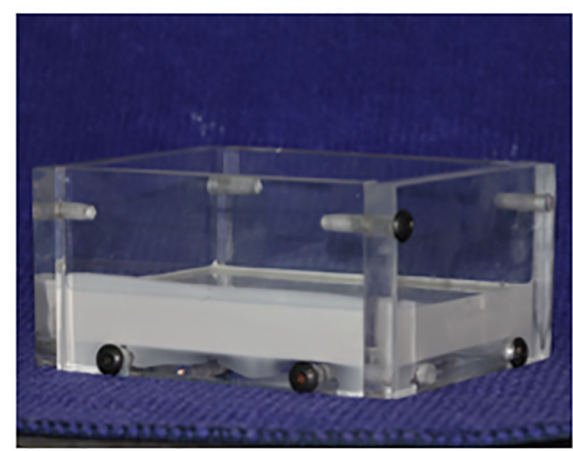

(c)

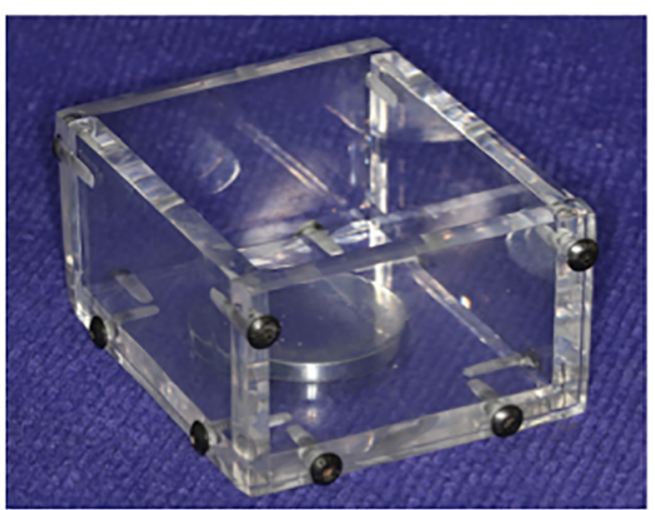

(b)

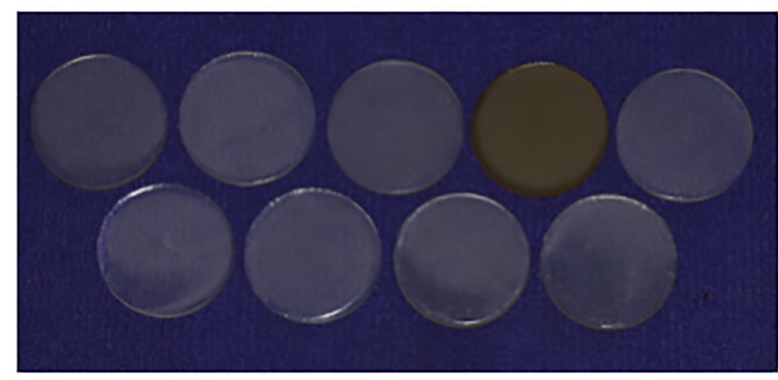

(d)

Figure 1.

A very common fact related resin handling is the formation of bubbles during the incorporation of the resin to the catalyst material, and their permanence even after the model is polymerized. For preventing this, handling was slowly performed, for 12 to 15 minutes, being slowly poured into the space left by the matrix. In relation to the resin PL2, the kit mould/resin was submitted to a constant pressure of 30 psi during six hours, inside the Bubble Eliminator for Orthodontic Apparels (VH). A smooth surface was then obtained. Nevertheless, a not good ideal goal persists: bubbles within the resin. 


\subsection{Photoelastic Trial}

Aiming at the analysis of sensitivity of the specimens of photoelastic resins, each disc was submitted to a diametral concentrated load ${ }^{6}$, while observed in a circular polariscope (CDTN), under white light or monochromatic light, to get the material photoelastic constant value $\left.{ }_{\sigma}^{(\mathrm{f}}\right)$ for each material.

$$
\mathrm{f}_{\sigma}=8 . \mathrm{P} /(\pi . \mathrm{D} . \mathrm{N})
$$

In equation (1), $\mathrm{P}$ is the applied load (Newtons), $\pi$ is a constant equal to $3,1416, \mathrm{D}$ is the disc diameter (m) and $\mathrm{N}$ is the fringe order passing through the center of the disc.

Having in mind the possible effects of buckling from the load application device, the first fringe was always adopted as a reference value for calculating the constant fo. By knowing this constant, the loads necessary for generating the next fringe orders one can calculate by a simple equation. In Chart 2, a general view of the obtained results is given.

Buckling of the model was a reference to stop increasing additional loads. Besides, loads above 150 Newtons were another reference taken into account for interrupting the test $(\mathrm{N}=1)$, since values near 150 Newtons meet the masticatory load at the molar region'.

Images were captured with a photo camera ( $\mathrm{T} 2 \mathrm{i}-\mathrm{Cannon})$ for each first order fringe formed $(\mathrm{N}=1)$, either for white light

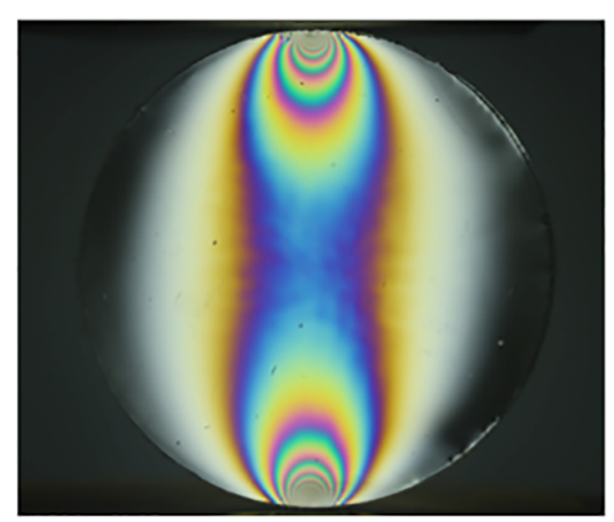

(a) or monochromatic light besides the existence of residual stress, after stop increasing the loads. Figure 2 illustrates the images obtained for Model 1.

\subsection{Image Simulation}

Once having the model dimensions and the photoelastic constant values for each material, other load increments were applied, to test the material behavior in face to different requirements, using SIMFOT ${ }^{20}$ software. Five photoelastic tests were simulated for a disc having the same radium and thickness, under several diametral compression loads, the only variation being the photoelastic constant (Chart 3)

\section{Results}

Simulations' performed with the first order fringe result generated images in gray levels similar to those obtained in a conventional photoelastic test for all the models. Based on the analysis of the images generated, one concludes that the smaller the photoelastic constant, the more sensitive is the material

It was noticed, under simulation, that the Flexible GIV resin (Figure 3), under a load of only $20 \mathrm{~N}$, although not having generated many fringes when compared to the models in Araldite Resin, PL2 and Rigid GIV, presented areas beyond the elastic regimen. When load was doubled

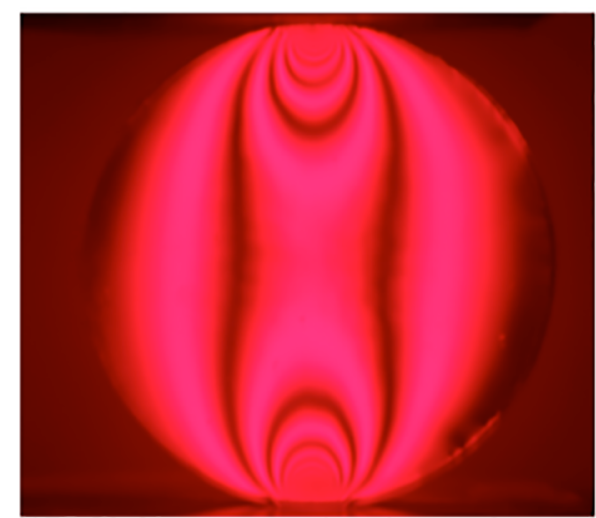

(b)

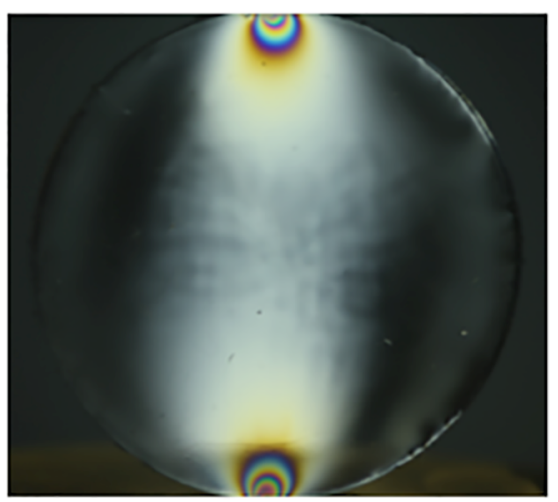

(c)

Figure 2. 
Chart 3. Resin dimensions, photoelastic constants, applied loads and images obtained

\begin{tabular}{|c|c|c|c|c|c|}
\hline Resins & Diameter (cm) & Thickness (mm) & $\begin{array}{c}\text { Photoelastic } \\
\text { constants }(\mathrm{N} / \mathrm{m})\end{array}$ & $\begin{array}{c}\text { Applied } \\
\text { loads (N) }\end{array}$ & Reference to images \\
\hline Flexible GIV & 50.5 & 5 & 261.4 & 20 & \\
\hline Araldite & 50.5 & 5 & 7197.8 & 20 & \\
\hline PL2 & 50.5 & 5 & 3573.1 & 20 & \\
\hline Araldite & 50.5 & 5 & 7197.8 & 150 & \\
\hline Flexible GIV & 50.5 & 5 & 261.4 & 40 & \\
\hline
\end{tabular}

(Figure 7), this fact became still more clear, justifying its low photoelastic constant value (261.4). For the aim of this work, this material is not recommended due to its high sensitivity in face of low load values.

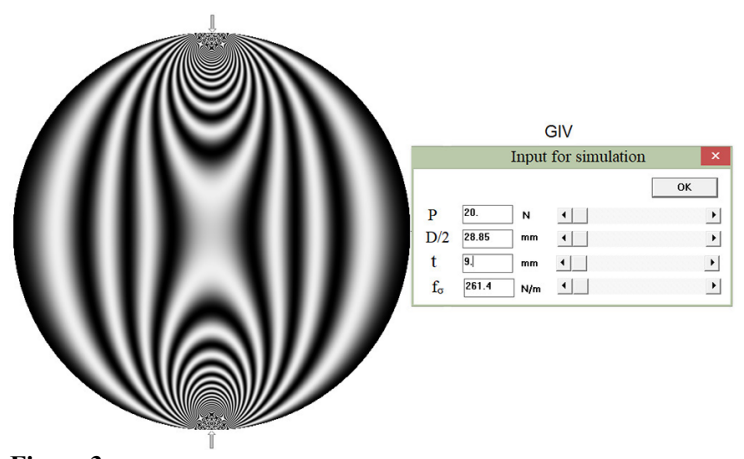

Figure 3.

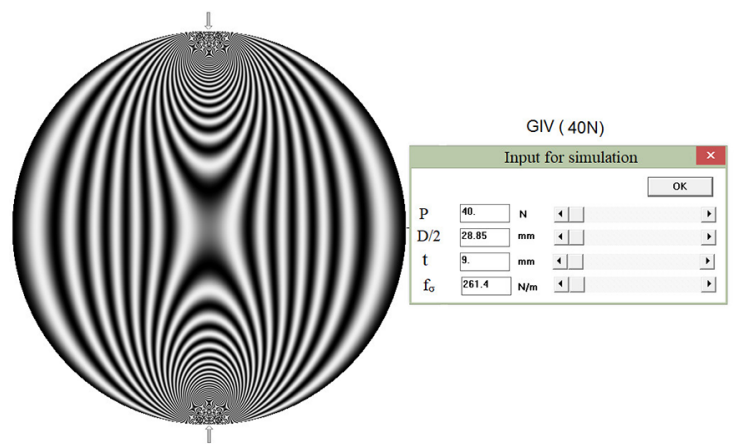

Figure 7.
Under simulation, Araldite resin under load of 20N (Figure 4) behaved well within the elastic regime and under load of $150 \mathrm{~N}$ (Figure 6), no areas with excessive concentration of fringes were observed. One notices that there was no formation of residual stresses for this material. Many residual stresses were observed for PL2 Resin, after ceasing load, which persisted for more than $30 \mathrm{~min}$, although the load had already been suspended. Bubbles persisted within the model after the final cure of the material. Even under constant pressure in the interior of a bubble eliminator ( $\mathrm{VH}$ ), during all the time of curing, the bubbles persisted in several model tested. This fact, on its own, contraindicates the material for a photoelastic test, since the material is expected to be homogeneous. The first order fringe for the Rigid GIV Resin was only formed under a load of 280 N. Furthermore, residual stresses were observed in the model after stop load increasing, according to Figure 2c. For the models generated from the manual mixture of Flexible GIV and Rigid GIV resins, in different ratios, one can do the following observations:

- Model 2 (75\% R + 25\% F): Excessive residual stress, the first order fringe being formed at a $21 \mathrm{~N}$ load.

- Model 3 (50\% R + 50 F): No residual stress was noticed, first order fringe occurred at a $12.6 \mathrm{~N}$ load.

- Model 4 (25\% R+50\% F): No residual stress observed, the first order fringe occurred at a $11.6 \mathrm{~N}$ load and the model buckled at the second increment.

- Model 6 (90\% R+10\% F): No residual stress observed, the first order fringe happened at a $3.9 \mathrm{~N}$ load, and the model buckled at the second increment. 
- Model 7 (95\% R + 5\% F): No apparent residual stress, the first order fringe took place at a $3.0 \mathrm{~N}$ load.

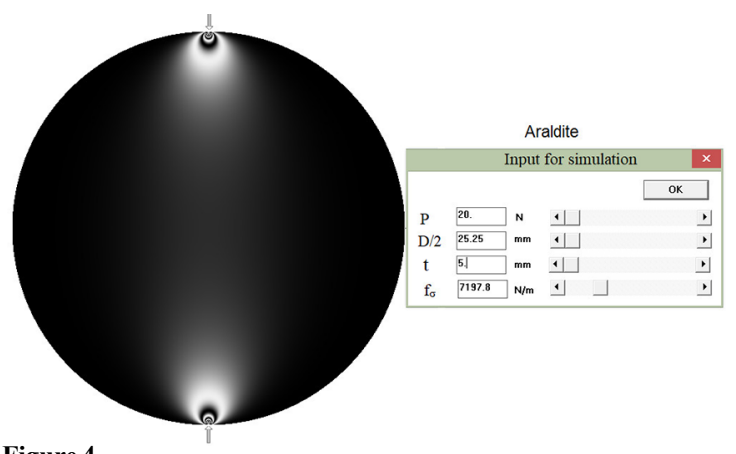

Figure 4.

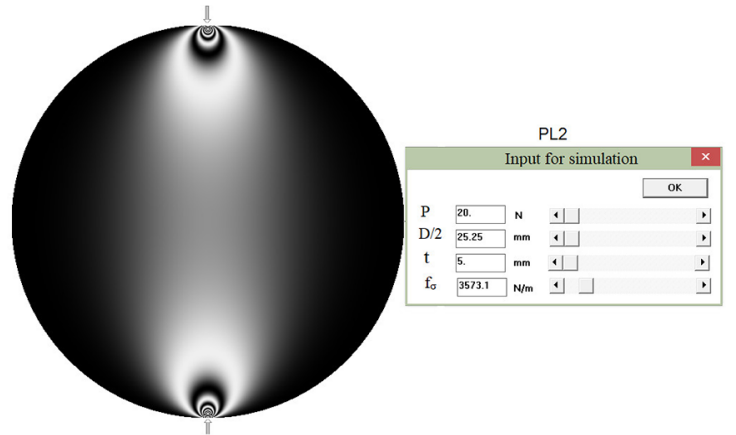

Figure 5.

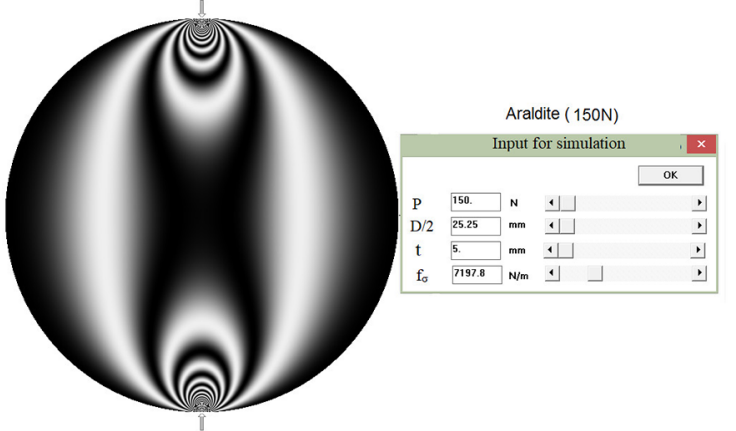

Figure 6.

One can note that, despite the homogeneous visual aspect, all the models obtained from those mixtures, when under load and observed in a polariscope, displayed images of non-homogeneous character, also presenting interruption of continuity at some points of the photoelastic fringes. No residual stress was observed for the Models 3 and 4, while for the models with greater ratios of Rigid GIV Resin (Models 1 and 2), internal stresses were seen after stop increasing the load.

\section{Discussion}

Almost two centuries after the discovery of the principles that guide the photoelastic technique ${ }^{1,6,24}$, issues and question still remain. These are not related to the technique and to the materials, but, actually, to simplifying what is the most relevant in a photoelastic test, that is, a resin that meets, the nearest as possible, the aim of researches. Reliability on the method can only be achieved from the principles that lie, mainly, on the correct choice of the photoelastic material. Ideally, the model stuff should emulate the behavior, in clinic conditions, of what one aims to reproduce ${ }^{1}$. The method applicability depends on the rapprochement between the clinical situation and the test condition. In this sense, relevance is in the occlusal loading simulation which best meets the desired situation one is planning to reproduce, since it is impossible to reproduce the oral tissues ${ }^{8}$. "Photoelasticity is easier to be used ... under loads that best emulate the real ones" 13.

The choice of the four brands of the tested resins in this study was based on a extensive recommendation in the pertinent literature for a two-dimensional photoelastic test Nonetheless, no dental studies were found that gave support for opting for a photoelastic resin to be used. As it can be seen, it seems clear that the choice of the material should meet the actual clinical situation. The following patterns were assessed for the photoelastic materials 1, 6, 10, ${ }^{17,21}$ : photoelastic sensitivity to the induced stresses, elastic regimen, transparence to the light used in the polariscope, homogeneity and residual stresses. And for the analysis of the material sensitivity, discs of different types of resin were used, all having the same diameter and thickness. Each disc was submitted to a diametral concentrated load, while observed in the circular dark field polariscope (CDTN). The secret for obtaining the photoelastic constant from the mentioned disc is to increase the diametral compression load until a certain fringe (its central part) passes through the central point of the disc. At this point, in particular, it is possible to calculate the photoelastic constant value based on the said numeric value by means of which the fringe is identified with the load compression value recorded by a load cell. Having in mind the possible effects of buckling resulting from the load application device, the first fringe was always adopted as the reference value for calculating the photoelastic constant $\left(f_{\sigma}\right)$. The values obtained for the constant $f_{\sigma}$ for each model were just references to enable the sensitivity of the researched materials. The results show, in a crescent scale of sensitivity, the following order: Model 7 (rigid GIV 95\% + Flexible GIV 5\%); Model 6 (Rigid GIV 90\%+ Flexible GIV 10\%); Model 9 (Flexible GIV); Model 4 (rigid GIV 25\% + Flexible GIV 75\%); Model 3 (rigid GIV 50\% + Flexible GIV 50\%); Model 2 (Rigid GIV 75\% + Flexible GIV 25\%); Model 5 (PL2); Model 8 (Araldite); Model 1 (Rigid GIV).

For checking if the photoelastic experiment was correctly conducted, images were generated in gray levels with a simulation software FOTOFRAN ${ }^{20}$, related to a disc under diametral compression load which, once given the disc dimensions, together with the photoelastic constant and at the load determined for the experiment. In this case, a pattern of isochromatic synthetic fringes similar to the ones in the 
experiment should be generated. The simulation process is very important, once the photoelastic constant is obtained, it is possible to foreseen the expected behavior of isochromatic fringes for greater magnitude loads.

In relation to the model loadings, the loads must be applied directly on them and should not exceed and not even get too near the resistance limit of the photoelastic resin, since two facts may occur: the breaking of the model when its fracture resistance limit is exceeded, or the jeopardizing of the results, when the work is not done within the elastic regime. This way, when considering the models in elastic regime and the magnitude of the required load at the molar region, the Araldite resin behaved within the elastic regime under a loading magnitude very near the interest value (168.5 N). In a diametrically opposed way, the Flexible GIV resin showed areas that went beyond the elastic regime at a mere $20 \mathrm{~N}$ load. At least for the dimensions of the test samples tested and under greater magnitude loads, it is not recommended to work with this resin. Other models suffered buckling when load increased, even before reaching $150 \mathrm{~N}$ (Model 4, at $12.8 \mathrm{~N}$ ). Meanwhile the model in rigid GIV resin, despite being worked within the elastic regime, had its first order fringe formed only at $280.3 \mathrm{~N}$ load, a performance far from the research aims.

As regards to the visual aspect, excluding the PL2 resin, all the others were translucent and colorless. PL2 resin showed a yellowish color ${ }^{15}$ and a yellowish hue in epoxy resins is inconvenient for its use as a photoelastic material. The transmission photoelastic analysis requires that the photoelastic material is transparent and features good optical proprieties ${ }^{18}$.

With regards to homogeneity, the physical properties of PL2 resin showed heterogeneity due to the bubbles presence in its interior. It is known that the use of pressure decreases, or even prevent incorporating those bubbles, without altering the properties of the resin. In this test, when finalizing the mixing time of PL2 resin, it was possible to notice a great bubble formation, which was not possible to totally remedy, even by using a constant pressure of 30 psi for 6 hours, inside a Bubble Eliminator for Dentistry Apparel (VH). This procedure was fundamental for reaching a smooth surface, although not totally free of bubbles. In relation to other resins, this procedure proved effective in just 20 minutes. An influence of the photoelastic material on the observed stresses on the stressed model could not be observed. Therefore, in the absence of load, this material should be free of residual stresses since those intrinsic stresses will interfere with the results. Furthermore, they make the material fragile and/ or favor spontaneous fractures. Taking into account the presence of residual stresses, and excluding the Models 3 , 4, 6 and 9, all the other models presented residual stresses, which is not the ideal. Finally, the lack of control on what is produced in face of the manual mixing among different resins can testify against the homogeneous final model. So, this procedure is contraindicated by this work.

\section{Conclusion}

According to the results obtained and the evidences presented, among the four tested resins brands, the Resin Araldite was the material that showed to be the most suitable for constructing the models with teeth and/or implants under masticatory load for a two-dimensional photoelastic test. Furthermore, it is necessary that a choice be made based on evidences, taking into account the kind of test to be performed, when choosing the material for photoelastic model analysis in dentistry studies.

\section{References}

1. Burger CP. Photoelasticity. In: Kobayashi AS, editor. Handbook on experimental mechanics. $2^{\text {nd }}$ ed. New York: VCH Publishers; 1993. p. $165-266$.

2. Carli IR, Pellizzer EP, Fálcon-Antenucci RM, Carvalho PSP, Verri FRE, Alves-Rezende MCR. Análise fotoelástica da distribuição das tensões no implante "platform switching". Revista Odontológica de Araçatuba. 2009;30(Supp1 1):819-822

3. Silva EF, Pellizzer EP, Mazaro JVQ, Garcia Júnior IR. Influence of the connector and implant design on the implant-toothconnected prostheses. Clinical Implant Dentistry and Related Research. 2010;12(3):254-262.

4. Micro-Measureaments. PhotoStress - Instruments. How to select photoelastic coatings. Tech Note TN-704-2. Document Number: 11213. Great Valley Parkway Malvern, PA: VPG Sensors; 2015; [access in 2011 jun 15]. Available from: www. micro-measurements.com

5. Dolan TJ, Murray WM. Photoelasticity. In: Hetenyi M, editor. Handbook of experimental stress analysis. New York: John Willey and Sons; 1966. p. 828-976.

6. Dally JW, Riley WF. Experimental stress analysis. New York: McGraw-Hill Book Company; 1991.

7. Freitas Júnior AC, Rocha EP, Assunção WG, Santos PH. Bioengenharia aplicada à Odontologia: método dos elementos finitos versus fotoelasticidade. Revista ImplantNews. 2007;4(5):469-476.

8. Glickman I, Roeber FW, Brion M, Pameijer JH. Photoelastic analysis of internal stresses in the periodontium created by occlusal forces. Journal of Periodontology. 1970;41(1):30-5.

9. Kiliaridis S, Kjellberg H, Wenneberg B, Engström C. The relationship between maximal bite force, bite force endurance and facial morphology during growth. Acta Odontologica Scandinavica. 1993;51(5):323-31.

10. Kuske A, Robertson G. Photoelastic stress analysis. New York: John Willey and Sons; 1974.

11. Matthys DR. Isochromatic fringes. Milwaukee, WI, USA: Marquette University, Physics Department; 1997.

12. Naves MM. Influência do contato interproximal em próteses fixas implanto-suportadas na mandibula edentada posterioranálise fotoelástica [dissertação]. Uberlândia (MG): Faculdade de Odontologia, Universidade Federal de Uberlândia; 2009. 
13. Pereira MGP, Smith Neto T, Almeida ID. Avaliação de franjas fotoelásticas simuladas no matlab e software de elementos finitos. $8^{\circ}$ Congresso Iberoamericano de Engenharia Mecanica; 2007 oct 23; Cusco, Peru. Cusco: Editora PUCP; 2007. p. 1-8.

14. Pigozzo MN, Laganá DC, Noritome PY. Avaliação das tensões às estruturas de suporte, por meio do método fotoelástico, decorrentes das forças aplicadas sobre overdentures retidas em implantes com sistema de encaixe barra-clipe. Revista de Odontologia da Universidade de São Paulo. 2010;22(2):111-121.

15. Pipes RB, Rose JL. Strain-optic law for a certain class of birefringent composites. Experimental Mechanics. 1974;14(9):355-360.

16. Quinan MAD. Uma metodologia para determinação do fator de intensidade de tensões causado por tensões térmicas utilizando a fotoelasticidade. São Paulo: IPEN - Autarquia associada à Universidade de São Paulo; 2005.

17. Rankilor PR, McNicholas JB. The preparation and use of a stress-sensitive material in multi-layer photoelastic models. International Journal of Rock Mechanics and Mining Sciences and Geomechanics Abstracts. 1968;5(6):465-474.

18. Ravi S. Development of transparent composite for photoelastic studies. Advanced Composite Materials. 1998;7(1):73-81.
19. Ribeiro JLS. Fundamentação da técnica fotoelástica, com a construção de um equipamento básico: polariscópio modelo [dissertação]. Belo Horizonte: Pontifícia Universidade Católica de Minas Gerais (PUC-MG); 2001.

20. Soares WS. Determinação de parâmetros da mecânica de fratura a partir de imagens fotoelásticas, usando processamento digital [thesis]. São Paulo: Instituto de Pesquisas Energéticas e Nucleares - Autarquia associada à Universidade de São Paulo; 1997.

21. Spooner H, McConnell LD. An ethoxylene resin for photoelastic work. British Journal of Applied Physics. 1953;4(6):181-184.

22. Srinivasan M, Padmanabhan TV. Implant prosthodontics: an in vitro photoelastic stress analysis. The Journal of Indian Prosthodontic Society. 2005;5(4):193-199.

23. Watanabe F, Uno I, Hata Y, Neuendorff G, Kirsch A. Analysis of stress distribution in a screw-retained implant prosthesis. The International Journal of Oral and Maxillofacial Implants. 2000;15(2):209-18.

24. Zak B. Photoelastiche analysis in der orthodontichen mechanik. Österreichische Zeitschrift fur Stomatologie. 1935;(33):22-37. 